\title{
SOCIEDADE EM REDE: PARAÍSO OU PESADELO? Reflexões acerca de novas formas de articulação social e territorial das sociedades ${ }^{1}$
}

\author{
RAINER RANDOLPH \\ IPPUR - Universidade Federal do Rio de Janeiro
}

O texto aqui proposto é uma tentativa de cristalização de alguns momentos de uma reflexão iniciada há vários anos e ainda não-encerrada. Ela o será algum dia?

Claude RAFFESTIN,

Por uma geografia do poder. (1993:5)

\section{Sucessivas aproximações a uma temática}

Este pequeno ensaio procura "cristalizar alguns momentos da nossa reflexão" a respeito do tema das redes. Apesar de a iniciarmos há alguns anos, não a encerramos - e nem temos previsão de fazê-lo num prazo previsível. Mesmo assim, seguindo o conselho de Raffestin, acreditamos ser útil expor as "cristalizações" de determinados momentos como já vimos fazendo nos últimos tempos.

No nosso trabalho o termo rede surge, inicialmente, como uma opção instrumental para caracterizar uma determinada realidade por ocasião de uma pesquisa documental sobre a articulação de movimentos sociais dos anos oitenta em áreas

\footnotetext{
${ }^{1}$ Uma primeira versão deste trabalho foi apresentado, em dezembro de 1997, na IV Semana de Planejamento Urbano e Regional do Instituto de Pesquisa e Planejamento Urbano e Regional IPPUR / UFRJ , Rio de Janeiro.
} 
(cidades médias) não metropolitanas do Sudeste ${ }^{2}$. Identificamos a presença - e seu envolvimento significativo - de uma ampla gama de "agentes" externos nestes movimentos (locais) em diferentes escalas sociais e territoriais. ${ }^{3}$ Acabamos chamando as articulações de "redes de solidariedade" que pareciam ser elemento importante de viabilização e sustentação dos próprios movimentos ${ }^{4}$.

Entretanto, envolvidos na época mais em questões de ecologia, meio ambiente e conflitos territoriais, não nos demos conta de imediato que a idéia da rede, como apontado por Ilse Scherer-Warren, oferece a potencialidade de "pensar, desde o ponto de vista epistemológico, na possibilidade de 'integração da diversidade'... . Distingue-se da idéia de 'unicidade' totalizadora, comum em interpretações do marxismo positivista acerca da necessidade de articulações das lutas sociais" (1993:9). Foi, então em momento posterior e referente a um "objeto" totalmente diferente do anteriormente estudado que começamos a problematizar a questão das redes numa perspectiva teórica e epistemológica.

Durante a realização de um projeto de cooperação internacional ${ }^{5}$ junto à Cátedra de Administração Industrial da Universidade de Erlangen-Nuremberg no verão (inverno na Alemanha) de 1992/93, tivemos a oportunidade de estudar

${ }^{2}$ Vide Randolph, R, Silveira, C., Menegat, E. Solidariedade e Gestão Territorial: Indagações sobre a Atuação das Organizações Não-Governamentais no Brasil In: Novas e Velhas Legitimidades na Reestruturação do Território, org. por Marco Aurélio Figueredo Gomes, ANPUR, Faculdade de Arquitetura, UFBa, 1993, p. 77-88; ANPUR: Associação Nacional de Pesquisa e Pós-Graduação em Planejamento Urbano e Regional;

3 Apenas anos mais tarde, a partir de 94/95, essa "noção" vai se transformando num desafio para nossa reflexão teórica o que nos levou a buscar algo como um conceito de "rede"; portanto, no início e nos primeiros momentos não nos preocupamos, ainda, com a recuperação de sua trajetória histórica. Outros autores, vide por exemplo SANTOS, M. A natureza do espaço. Técnica e tempo. Razão e emoção. São Paulo: Hucitec, 1996 que dedica um capítulo à discussão da "geografia das redes"; DIAS, L. C. Redes: emergências e organização. In: Geografia: conceitos e temas, org. por CASTRO, I. E., GOMES, P.C., CORRÊA, R.L., R.J: Bertrand Brasil, 1995, pp. 141-162 e, de outra angulação, SCHERER-WARREN, I. Metodologia de redes no estudo das ações coletivas e movimentos sociais. In: Anais do VI Colôquio sobre Poder Local (1994), NPGA/UFBa, Salvador, 1996, pp. 129-142, o fizeram e localizaram as origens do conceito na passagem do século XVIII a XIX na química e depois no pensamento saint-simoniano do século XIX. A investigação dos documentos e dados sobre as assim chamadas "experiências participativas" (reunidas pelo IBASE) resultou mais tarde numa discussão sobre o assim chamado "terceiro setor"; vide RANDOLPH, R. A formação do "Terceiro Setor" no Brasil. Reflexões e indagações empíricas. In: Desenvolvimento social. Desafios e estratégias, org. p. Maria I. D’Ávila Neto, Rio de Janeiro: UNESCO-UFRJ/EICOS 1995, pp. 85-106;

${ }^{4}$ O trabalho "Solidariedade e gestão territorial" tinha sido apresentado na ANPUR em 1991; apenas dois anos depois tivemos acesso a um trabalho específico de Ilse SCHERER-WARREN que confirmou nossa interpretação: vide SCHERER-WARREN, I. Redes de movimentos sociais. São Paulo: Loyola, 1993

${ }^{5}$ Financiado por CAPES e DAAD (Intercâmbio Acadêmico da Alemanha) sob o título: "Novas formas de gerenciamento empresarial e suas consequências para o desenvolvimellto regional'”. 
novas formas de gerenciamento empresarial - em particular o então em moda ${ }^{6}$ "Lean Mangement"- na passagem do fordismo para o pós-fordismo. O confronto entre as abordagens instrumentalistas correntes na administração de empresas com a análise de Harvey (1989) nos fez levantar a hipótese que estas propostas deviam ser analisadas não apenas como mais um método (ou receita) de otimização do empenho das empresas, mas como sinal de uma mudança que admitia as limitações, ao menos parcialmente, da própria lógica instrumental que sempre guiava a organização formal das empresas fordistas. Uma das consequências diretas destas modificações pareciam-nos, seguindo as análises de um autor alemão (SYDOW, 1992) da área de administração, as redes estratégicas que expressam um novo ${ }^{7}$ arranjo de funções produtivas e administrativas dentro e entre empresas que representam um padrão qualitativamente diferente em relação a reformulações anteriores.

Dentro dos marcos conceituais da teoria social crítica de Habermas ${ }^{8}$ procuramos compreender o surgimento tanto de "redes de solidariedade" como de "redes estratégicas" como sinal de uma profunda transformação da sociedade capitalista contemporânea. Adotando os conceitos de "sistema" e "mundo da vida" do autor acima referido, este "duplo movimento" parecia significar algum deslocamento das barreiras entre mundo da vida e sistemas econômicos e administrativos; a hipótese da "rede" permitiu, conforme nossa compreensão, enxergar um "paralelo oposto" ("dialética") entre as propostas de redes estratégicas e as de redes de solidariedade. Mesmo a incomparabilidade aberta entre essas duas experiências (pontuais) não nos parecia dificultar sua compreensão como expressão diferente de uma transformação; ao contrário, parecia indicar exatamente o caráter heterogêneo e heterodoxo, contraditório num novo sentido, dessas mudanças 9.

Procuramos, desde então, fundamentar melhor estes argumentos, tanto teórica, como empiricamente ${ }^{10}$; investigamos, em 1994, formas de consumo que seguiam os "mesmos" caminhos "reticulares", porém, com características bastante diversas ${ }^{11}$.

\footnotetext{
${ }^{6} \mathrm{Na}$ Alemanha foram publicados entre 1992 e 1993 uma série de livros de professores universitários a respeito deste tema: $v$ ide inclusive do colega com o qual se deu nossa interlocução principal no mencionado projeto de cooperação internacional: Pfeiffer, W. e Weiss (1992).

${ }^{7}$ A "novidade" deve ser compreendida como hipotese: obviamente a articulação entre empresas entre si e com seu ambiente sempre esteve sujeita a rearranjos. Mas pareceu-nos que nas propostas do Lean Mangement apareciam elementos que se diferenciaram das experiências anteriores; vide uma primeira abordagem nossa em Randolph (1993)

${ }^{8}$ Particularmente conforme expressa na sua teoria da ação comunicativa que ainda será objeto de uma discussão mais aprofundada no decorrer deste ensaio; vide Habermas, J. (1981/82)

${ }^{9}$ Já a partir de abril de 1993 apresentamos estas idéias em três seminários e encontros: no seminário acima mencionado, no Encontro Nacional da ANPUR e no 3 ${ }^{\circ}$ Simpósio de Geografia Urbana no Rio de Janeiro; vide RANDOLPH (1993) e RANDOLPH (1994)

${ }^{10}$ Com o apoio. inclusive. de projetos de pesquisa da FINEP e de apoios integrados do CNPq;

11 Vide RANDOLPH, R. "American way" e redes brasileiras: Novas formas de consumo e sua expressão nas novas redes territoriais.In: Modernidade, exclusão e a espacialidade do futuro, org. por R.L.Farret (Anais do Vi Encontro Nacional da ANPUR 1995) Brasília: ANPUR, 1996, pp. 1053-1064;
} 
A busca por outras "manifestações" deste "deslocamento de fronteiras" nos levou a investigar novas propostas de um planejamento qualificado de "comunicativo"12 que dirige sua atenção (e proposição) para novas formas de articulação entre poder público (Estado, governo) e sociedade, partindo de um ponto de vista da atuação administrativa no caso. Neste contexto foi o próprio conceito de "comunicação" que se tornou foco principal do nosso debate e demonstrou uma potencialidade de levar adiante as preocupações que antes se expressaram nas formas solidárias de redes $^{13}$. Ao mesmo tempo, a reflexão sobre a comunicação levou a uma ampliação essencial desta trajetória conceitual e empírica que se deu através da incorporação das novas tecnologias de informação e comunicação neste universo das redes.

São particularmente as comunicações mediadas por computadores (Computer Mediated Communication - CMC) que atraíram nossa atenção ${ }^{14}$, a partir de 1995 , enquanto sustento, fundamento e meio indispensável para a realização e avanço de quase todas as outras experiências (mesmo as das redes de solidariedade), como também por causa de sua força promotora própria que tende a criar novas formas de articulações (econômicas, sociais, políticas e culturais). Em consequência, dedicamos cada vez mais esforço à investigação e exploração da "rede das redes": da Internet e seu funcionamento enquanto tecnologia (rede) que modifica formas tradicionais de troca, intercâmbio, comunicação e integração social ${ }^{15}$.

Se o "Clube do Futuro" já prenunciava a necessidade de buscar caminhos coletivos, a progressiva identificação de outros pesquisadores brasileiros envolvidos nesta temática possibilitou uma série de atividades conjuntas, respeitando, obviamente, os objetos e preocupações particulares de cada um e as diferenças significativas entre os posicionamentos teóricos, abordagens metodológicas e estudos empíricos. Assim, sacramentada em Assembléia Geral no VI Encontro Nacional da ANPUR em 1995, em Brasília, formamos uma pequena rede de pesquisadores que procuram, através de um intercâmbio mais ou menos sistemático e freqüente,

\footnotetext{
${ }^{12}$ Em uma série de trabalhos, desde 1994, estamos discutindo na ANPOCS as potencialidades, limitações e deslocamento de "fronteiras" entre Estado e sociedade; vide em particular as idéias apresentadas em 1995 em RANDOLPH, (1996c); no presente ano (1997) tivemos a oportunidade de expor uma última versão deste raciocínio na ANPOCS; vide RANDOLPH, (1997c).

${ }^{13}$ Neste sentido, procuramos, ainda no âmbito desta VI Semana de Planejamento Urbano e Regional do IPPUR contribuir para esta discussão com um trabalho sobre redes associativas: RANDOLPH, R. Sujeitos complexos, redes associativas e territórios do poder. Rio de Janeiro, IPPUR/UFRJ, dez. 1997;

${ }^{14}$ Estimulado e incentivado pelos nossos colegas do Clube do Futuro no IPPUR, idealizado neste momento, Frederico Araujo, Giuseppe Cocco e, em particular, Nilton B. Santos;

${ }^{15}$ No caso procuramos articular essas redes com a estruturação urbana e suas possíveis mutações; vide os primeiros resultados apresentados em (1996d): RANDOLPH (1996d): e no último Encontro Nacional da ANPUR em maio de 1997: RANDOLPH (1997a); vide também as interessantes proposições de SCHERER-WARREN (1997):
} 
contribuir para o aprofundamento da reflexão acerca das diferentes manifestações de redes ${ }^{16}$. Em outubro de 1996 realizou-se, então, o $1^{\circ}{ }^{\circ}$ Workshop sobre Redes no Rio de Janeiro com a presença de pesquisadores do sul ao norte (nordeste) do país 17 .

Como expressão deste esforço foi possível, no VII Encontro Nacional da ANPUR em Recife (1997), organizar uma mesa de debate sob o tema: "Redes: metodologias em construção" onde uma boa parte dos pesquisadores que mais tem se destacado no estudo de redes apresentaram suas reflexões e os resultados de suas pesquisas. Dando continuidade em certa medida a essa linha de investigação, no encontro mais recente dessa Associação (o oitavo realizado em 1999 em Porto Alegre) debatemos em duas mesas questões relacionadas com o avanço das tecnologias de informação e comunicação no meio urbano sob o título de "Telecidades".

Após toda essa trajetória, qual é a síntese que pode resumir os resultados dos estudos, análises, reflexões e debates? Dentro do contexto (intenções) do atual trabalho basta apontar uma percepção que foi se repetindo em relação a cada transformação ou tendência de mudança que investigamos: primeiro, sempre identificamos, comparado a padrões ou paradigmas de compreensão tradicional (tanto funcionalistas como críticos), este caráter heterogêneo das redes já acima apontado, sua composição por partes "incompatíveis" de diferentes lógicas, origens, trajetórias, mas mesmo assim articuladas e "integradas" numa nova "unidade". E, segundo, o caráter profundamente ambíguo e ambivalente das transformações expressas nestas novas redes em relação ao aprofundamento ou à superação dos antagonismos, contradições e conflitos que caracterizam, em diferentes graus, as sociedades que supomos estarem em algum processo de transição.

Em outras palavras, parece que as transformações estão encaminhando um novo "padrão" de antagonismos e contradições nas "novas" sociedades do qual temos "sinais", ao nosso ver, ainda ambivalentes e ambíguos que não ousamos antever a partir do conhecimento que conseguimos acumular. Portanto, falar já de uma sociedade-rede pareceria no mínimo precipitado na medida em que não sabemos se e como esta "lógica de rede" se tornará dominante nas sociedades pósfordistas.

\footnotetext{
${ }^{16}$ Cabe mencionar ainda os trabalhos apresentados no I. Colóquio sobre Redes Produtivas, organizado na Escola de Ciências Econômicas da UFBa em Salvador no mesmo ano;

${ }^{17}$ Contava com a presença dos seguintes pesquisadores: Zila Mesquita da UFRGS, Tamara Benakouche e Leila Dias da UFSC, Claudette Junqueira da USP, Roberto Lobato Correa e Marcelo José de Souza do IGEO/UFRJ, Frederico Araujo, Giuseppe Cocco, Mauro Kleiman e Nilton B. Santos do IPPUR/UFRJ, Carlos Alberto Messeder Pereira da ECO/UFRJ, Rogério Haesbaert e Ester Limonad da UFF, e de Monica Raposo Andrade e José Carlos Cavalcanti da UFPE;
} 
Foi então, neste momento da nossa própria reflexão, que tivemos acesso a um livro com um título sugestivo: o ascensão da sociedade-rede - "The rise of the network society" de Manuel Castells ${ }^{18}$, um velho conhecido desde sua "Questão urbana" da década de sessenta e seus trabalhos sobre movimentos sociais, novas tecnologias, tecnopólis e outros assuntos desde a década de oitenta.

Procuramos, então, aproveitar a investigação verdadeiramente global de Castells para reunir mais elementos a respeito da questão central que nos mobiliza em relação às novas formas de articulação social e territorial das sociedades contemporâneas: uma vez que partimos do pressuposto de que qualquer "sociedaderede" continua sendo, pelo menos inicialmente, uma sociedade capitalista, como será o novo "desenho" dos antagonismos e seus protagonistas, das contradições e conflitos, das formas de inclusão e exclusão e seus sujeitos/agentes.

Ou seja, do ponto de vista de uma perspectiva crítico-emancipatória, estas sociedades serão capazes de resolver os problemas (econômicos, sociais, políticos, culturais) das sociedades capitalistas contemporâneas. Prometerão, assim, o "paraíso"? Ou vão aprofundar e radicalizar ainda formas atuais de desigualdades e exclusão social e política, de violência e crises - portanto, configurar-se como um pesadelo ${ }^{19}$

"The rise of the network society" pode dar uma importante contribuição para estas inquietações; portanto, propomo-nos, em seguida, apresentar um resumo das conclusões que Castells tira ao final do seu livro.

\section{Oposição fundamental na sociedade em rede}

Na parte final de "The rise of the network society" Castells aponta que a exploração das estruturas sociais emergentes, realizada no decorrer dos capítulos anteriores, referentes a diferentes domínios de atividades e experiências humanas, o leva a uma inquestionável conclusão: como tendência histórica, funções e processos dominantes na era da informação estão organizados, cada vez mais, em torno de redes (CASTELLS, 1996:469). Mais genericamente do que jamais ousamos defender, o autor afirma que "redes constituem a nova morfologia social de nossas sociedades, e a difusão da lógica de rede modifica substantivamente a operação e o resultado dos processos de produção, experiência, poder e cultura".

\footnotetext{
18 Vide CASTELLS, M. The rise of the network society. Malden, Mass, Oxford. UK: Blackwell Publ., 1996, reimpressão: 1997 como primeiro volume de sua obra maior sobre a "Era da Informação" (The Information Age. Economy, Society and Culture); os primeiros dois volumes dessa trilogia já estão agora também disponíveis em português;

${ }^{19}$ Sabemos que estas generalizações são questionáveis num mundo que se "globaliza" fragmentadamente; devem ser compreendidas como analiticamente necessárias para podermos desenvolver nosso argumento num espaço restrito.
} 
Em princípio, esta forma de organização social - em rede - já existia em outros tempos e espaços (períodos e territórios); mas, o novo paradigma da tecnologia de informação fornece a base material para uma expansão persuasiva para dentro da estrutura social inteira. Castells argumenta que essa lógica de produzir redes ("networking" 20 ) induz uma determinada lógica social que se localiza num patamar superior daquela onde os interesses sociais específicos se expressam através das tradicionais redes (de influência). De uma maneira sintética aponta que, hoje, o poder de fluxos assume uma precedência em relação aos fluxos do poder (CASTELLS, 1996:469).

É esta idéia que ele vai explicitar mais detidamente neste capítulo conclusivo após ter percorrido, já o mencionamos, uma análise de experiências de todas as partes do mundo.

Qual a conclusão, então, em relação ao ponto que nos interessa particularmente? Afirma Castells (1996:476) que sob as condições da sociedade-rede, "o capital é coordenado globalmente, o trabalho é individualizado. A luta entre diversos capitalistas e classes de trabalhadores miscelâneos está subsumida à oposição mais fundamental entre a lógica nua de fluxos de capital e os valores culturais da experiência humana" (grifos nossos).

Esta conclusão é resultado de uma ampla reflexão do autor acerca das novas relações entre capital e trabalho que se instalam na sociedade-rede. Na medida em que este é o ponto chave para nosso próprio trabalho, vamos aprofundar os argumentos do autor que sustentam sua interpretação.

Nossa investigação sobre redes estratégicas andou apontando em direção semelhante. Conforme Castells ${ }^{21}$ :

as observações e análises apresentadas neste primeiro volume parecem indicar que a nova economia está organizada em torno de redes globais de capital, administração de empresas e informação cujo acesso ao saber tecnológico (know-how) está nas raízes da produtividade e competitividade. Firmas de negócios (business firms) e, cada vez mais, organizações e insti-tuições são organizadas em redes de geometria variável cujo entrelaçamento suplanta as tradicionais distinções entre corporações e pequenos negócios, atravessando setores e espalhando-se ao longo de diferentes clusteres geográficos de unidades econômicas. De acordo com isto, o processo de trabalho é cada vez mais individualizado, o trabalho é

\footnotetext{
${ }^{20}$ Criamos em outro lugar um neologismo para esta expressão "networking" que está sendo usada amplamente na bibliografia anglo-saxã para apontar o caráter dinâmico da construção e modificação de redes: pensando na "edificação" de "redes" chegamos a propor o termo "rede-ficação"; vide RANDOLPH (1993a)

${ }^{21}$ Traduzimos a seguir de uma forma relativamente livre os trechos importantes, porém o mais próximo ao texto possível; mesmo assim, recomenda-se um certo cuidado na leitura do nosso texto que reflete uma dose significativa da nossa compreensão do raciocínio (não pode ser lida como tradução "autorizada").
} 
desagregado na sua performance e reintegrado no seu resultado através de uma multiplicidade de tarefas interconectadas em diferentes lugares, conduzindo a uma nova divisão do trabalho baseada mais nos atributos e capacidades de cada trabalhador do que na organização das tarefas" (1996:471).

Reforçando um argumento que já usamos anteriormente, o autor também afirma que a propagação e ampliação das redes (networking) no interior e entre empresas, corporações e mesmo organizações que não visam o lucro não podem ser interpretadas como falecimento do capitalismo. Ao contrário, representa uma jamais vista expansão do modo de produção capitalista que molda relacionamentos sociais ao redor do planeta inteiro. "A sociedade-rede, nas suas várias expressões institucionais, é e continuará por algum tempo uma sociedade capitalista".

Mas esta marca do capitalismo é profundamente diferente dos seus antecessores históricos. Tem duas fundamentais e distintivas propriedades: é global e estruturada em larga medida em torno de uma rede de fluxos financeiros. O capital trabalha globalmente como uma unidade em tempo real; e ele é realizado, investido e acumulado principalmente na esfera da circulação, isto é, como capital financeiro. Apesar de que o capital financeiro geralmente esteve entre as frações dominantes do capital, nos estamos testemunhando a emergência de algo diferente" (1996:471)

A acumulação do capital procede, e seu valor-acréscimo é gerado, cada vez mais, nos mercados financeiros globais promulgado através de redes de informação no espaço sem tempo dos fluxos financeiros. A partir destas redes o capital está investido, globalmente, em todos os setores de atividade (1996:472).

Estabelece-se aquilo que o autor chama de um cassino global onde, operados eletronicamente, capitais específicos crescem rapidamente ou desvanecem (boom or bust), determinando o destino de corporações, poupanças de domicílios (famílias), moedas nacionais e economias regionais. É um jogo de soma zero: os perdedores pagam para os ganhadores. Mas, quem são ganhadores e perdedores muda durante o ano, o mês, o dia, o segundo e se dissemina para baixo para o mundo das firmas, dos postos de trabalho (jobs), salários, impostos e serviços públicos. Atinge, então, o mundo que costumamos chamar de "economia real". Mas que Castells é levado a compreender como verdadeira "economia irreal", porque na era do capitalismo em rede a realidade fundamental, onde dinheiro é ganho e perdido, investido ou poupado, é a esfera financeira.

O capital financeiro, agindo diretamente através de instituições financeiras ou indiretamente através da dinâmica do mercado nas bolsas de valores, condiciona o destino das indústrias de alta tecnologia".

"Por outro lado, tecnologia e informação são instrumentos decisivos na geração de lucros e apropriação de participação de mercado. Por isto, capital financeiro e alta tecnolo- 
gia são cada vez mais interdependentes, mesmo quando seus modos de operação são específicos para cada indústria....

Por isto, o capital ou é global ou se torna global quando entra no processo de acumulação na economia rede-ficada (networked) por vias eletrônicas (1996:473).

Procurando indicar os protagonistas destes processos (e as conseqüentes contradições) pergunta quem serão, então, os capitalistas? Não são mais, é óbvio, os proprietários legais dos meios de produção, nem os administradores das corporações, o que não surpreende muito. Existe uma grande heterogeneidade entre os "capitalistas" (todos são). Mas, existe uma classe capitalista?

Não existe uma coisa, sociológica e economicamente, como uma classe capitalista global. Mas existe uma integrada rede capitalista global cujos movimentos e lógica variável determinam economias e influenciam sociedades. Portanto, para além de uma diversidade de capitalistas de carne humana e grupos capitalistas existe um capitalista coletivo sem rosto, gerado por fluxos financeiros em redes eletrônicas. Isto não é simplesmente a expressão de uma lógica abstrata de mercados porque não segue verdadeiramente a lei da oferta e demanda: responde às turbulências e movimentos imprevisíveis, antecipações incalculáveis, induzidas tanto por psicologia e sociedade, como por processos econômicos. Esta rede de redes do capital unifica e comanda centros específicos da acumulação capitalista, estruturando o comportamento de capitalistas em torno da sua submissão à rede global. Eles jogam suas estratégias competetivas ou convergentes com e através dos circuítos dessa rede global, e assim eles estão dependentes, em última instância, da lógica capitalista não-humana do processamento random (por acaso) de informações, operado eletronicamente. Isto é de fato capitalismo na sua expressão pura da busca infinita do dinheiro com dinheiro através da produção de mercadorias por mercadorias. Mas, o dinheiro já se tornou em larga medida independente da produção, inclusive produção de serviços, na medida em que escapa para redes de interações eletrónicas de alta ordem dificilmente compreendidas por seus administradores" $(\text { grifos nossos) })^{22}$.

Após esta "dissolução ou fluidificação" do capital (sob dominação do financeiro) nas redes globais dos fluxos de informações, o que, pergunta-se o autor, aconteceu com o trabalho, os trabalhadores e as relações sociais de produção? Os

\footnotetext{
${ }^{22}$ Idem, p. 474; seria interessante e importante seguir mais detidamente este argumento da centralidade do capital financeiro; pela concepção de Arrighi, por exemplo, a "financeirização" já não é o sinal dos novos tempos, mas um indício de declínio do velho que se repetiu em todos os grandes ciclos da economia e sociedade ocidentais; vide Arrighi, 1996.

${ }^{23}$ Um conceito que Castells trabalha num capítulo próprio de seu livro;
} 
trabalhadores não desapereceram (no "espaço dos fluxos"23) e, apesar de todos os problemas basicamente na Europa, afirma que o trabalho é farto (1996:474).

Entretanto, mesmo existindo trabalho, trabalhadores e classes de trabalhadores, o relacionamento social entre capital e trabalho se transformou profundamente.

"Na sua essência, o capital é global. Como regra, o trabalho é local".

A difusão atual dos instrumentos da informática e telemática (informacionalismo), leva à concentração e globalização do capital, precisamente através do uso do poder descentralizante de redes. Estas, como vimos antes, convergem em direção a uma meta-rede do capital que integra os interesses capitalistas ao nível global e perpassando setores e domínio de atividades, não sem conflitos, mas sob a mesma lógica subjacente.

Por outro lado, o trabalho é desagregado no seu desempenho, fragmentado na sua organização, diversificado na sua existência, dividido na sua ação coletiva. Enfim, o confronto entre essas características gera a oposição que antes apontamos:

O trabalho perde sua identidade coletiva, torna-se cada vez mais individualizado nas suas capacidades, nas condições de trabalho, e nos seus interesses e projetos. Quem são os proprietários, os produtores, os admi-nistradores e os ajudantes torna-se cada vez mais indistinto num sistema de produção de geometria variável, trabalho em grupo, networking, outsourcing e subcontratação. ... Assim, enquanto o relacionamento capitalista persiste ainda (ora, em muitas economias a lógica dominante é mais estreito capitalista que nunca antes), capital e trabalho tendem a existir, cada vez mais, em espaços e tempos diferentes: o espaço dos fluxos e o espaço dos lugares; tempo instantâneo de redes computadorizadas versus tempo de relógio da vida diária (cotidiana). Portanto, eles vivem um ao lado do outro, mas eles não se relacionam um com o outro como a vida do capital global depende cada vez. menos de trabalho específico, e mais e mais de trabalho genérico acumulado, operado por uma pequena elite intelectual (brain trust) morando nos lugares virtuais de redes globais" (1996:475).

Isto não quer dizer, nas palavras do autor, que para além da dicotomia fundamental não continue existindo uma grande parcela de diversidade social, formada por lances de investidores, esforço dos trabalhadores, ingenuidade humana, sofrimento humano, entrada e saída de empregos, promoções e rebaixamentos, conflitos e negociações, competição e alianças: a vida do trabalho continua.

Porém, num patamar mais profundo da nova realidade social, relações sociais de produção foram desconectadas $n \backslash d a$ sua existência atual. O capital tende a escapar no seu hiperespaço de pura circulação, enquanto o trabalho dissolve sua entidade coletiva numa variação infinita de existências individuais" (1996:475) 
$\mathrm{Na}$ sociedade-rede, as redes - e, em particular, a meta-rede (dos fluxos financeiros) - não resultam em uma "universalização" de conexões que pudessem superar (aniquilar) velhas separações, segregações ou até exclusões, mas apenas na mundialização do fluxo financeiro. Paradoxalmente, a sociedade-rede caracterizase por um grau de conexões mais baixo do que formas anteriores. A "distância" entre capital e a expressão coletiva das pessoas é infinita como Castells afirma em outro momento. A sociedade-rede é aquela onde uma rede (a citada meta-rede) torna-se dominante (entre os pares) e excludente (em relação aos trabalhadores e suas manifestações culturais e vitais) enquanto expressão de uma pureza da lógica capitalista nunca vista na história.

Em síntese, a sociedade-rede parece ser ambos: paraíso e pesadelo ao mesmo tempo. É o paraíso com o qual o capital sempre sonhou - a mistura entre Hilferding e Schumpeter como diz Castells - e o pesadelo que sempre ameaçou os trabalhadores e lhes roubou seu sono. O capitalismo tornado fluxo transcende qualquer limitação do tempo e do espaço.

\section{Trajetórias dos antagonismos e contradições}

A radicalidade da posição de Castells não deixa de ter seu fascínio, especialmente quando observamos em nossa volta um sistema financeiro mundial que parece enlouquecer sob o ataque dos "capitais especulativos" que perturbam há meses (após a primeira crise no sudeste asiático) as bolsas e governos no mundo inteiro. Dentro da visão que acabamos de apresentar assistimos muito mais um exercício "lógico" da meta-rede de superfluidez dos recursos financeiros do que um "desvio" do "bom capital" aplicado produtivamente (imaginamos que Arrighi corroboraria esta visão). A instabilidade que se instalou, a ameaça do caos, devem ser vistos, neste sentido, como conseqüências lógicas do novo "sistema" (da sociedade-rede) do que resultado temporário e excepcional de um comportamento desviante (especulativo).

Porém, apesar destes sinais de "confirmação" das conclusões de Castells, a "lógica" da sociedade-rede baseada na meta-rede mundial parece não comportar mais um antagonismo instrínseco a ela mesma (uma convivência de princípios antagônicos que é, dialeticamente falando, uma condição básica para sua existência); ou seja, na verdade, na sociedade-rede não há mais antagonismo na medida em que a contradição entre capital e trabalho tornou-se algo externo à prática

\footnotetext{
${ }^{24}$ É temerário tirar conclusões definitivas agora, que podem se revelar precipitadas na medida em que o autor ainda vai trabalhar outras características da sociedade-rede nos dois volumes da obra maior que estão sendo publicados agora (o segundo já foi lançado, mas ainda não tivemos acesso a ele). Para o segundo volume Castells anuncia temas como: "communal heavens: identity and meaning in the network society"; "social movements and social change in a world of flows"; e, como conclusão, "the subjects of social change in the network society".
} 
social e deixou de ser, portanto, um elemento do dinamismo social. Parece mesmo esta a consequência última do raciocínio de Castells quando fala do espaço dos fluxos e do tempo sem-tempo (timeless time). O fim da história? Ou mesmo o fim do capitalismo? ${ }^{24}$

Ora, a história do capitalismo mostra transformações onde determinados "formatos" de antagonismos e contradições vão-se seguindo dentro do seio da sociedade (formação social) capitalista. Acreditamos que uma breve recuperação de sua trajetória pode ajudar na contextualização e interpretação da possível ascensão de uma sociedade-rede ${ }^{25}$.

Cabe fazer, inicialmente, um breve comentário sobre o marco inicial dos antagonismos; contradições e conflitos endógenos como base da dinâmica social podem ser pensados apenas a partir de secularização e desencantamento iniciados pela modernidade há 300 anos atrás - quando se começou a compreender que o destino do homem (em sociedade) é de sua própria responsabilidade (e não resultado de uma força supra-"natural" que o determine; por exemplo, de uma "lei divina" ou de outras formas transcendentes).

Descartando abordagens que pregam a "auto-poeisis" de sistemas (perspectivas sistêmicas e/ou funcionalistas), distinguimos a trajetória mais recente dos antagonismos em dois períodos históricos (com suas duas leituras respectivas) e um período em vias de formação que exigirá igualmente sua maneira apropriada de análise; é na identificação e caracterização deste último período emergente que se inscrevem tanto as investigações de Castells a respeito da sociedade-rede; como também os nossos estudos e reflexões a respeito do surgimento de diferentes articulações econômicas, sociais e políticas em forma de redes.

(1) Relacionada a uma dinâmica das novas sociedades industrializadas em fase de consolidação na Europa ocidental dos meados do séc. XIX temos a leitura de Marx (e seus discípulos) que identifica, a partir de uma crítica à economia política clássica de Adam Smith e Ricardo, como lógica fundamental deste período o movimento contraditório entre avanço das forças produtivas e relações sociais de produção que mais cedo ou mais tarde irá desembocar num rompimento destas relações. É expressão do antagonismo fundamental e geral ou universal (base preponderante de integração social na medida em que se generaliza) nestas sociedades entre os proprietários dos meios de produção (que ditam as formas individuais da apropriação do produto socialmente criado) e aqueles que apenas possuem sua força de trabalho como mercadoria para vender, mas que lhes confere sua coesão e combatividade nas lutas contra a dominação exercida pela classe burguesa.

É, então, o "trabalho" e a apropriação do valor por ele gerado que estão no fundamento da organização destas sociedades ("de trabalho"). Se a dinâmica e o

${ }^{25}$ Vide para a argumentação que apresentamos a seguir também RANDOLPH (1997b). 
avanço destas sociedades se baseia no trabalho abstrato (forças produtivas), a contestação e possibilidade de sua negação origina-se na própria figura do trabalhador e de sua inserção produtiva nesta sociedade (relações de produção). É com referência ao trabalho e não-trabalho que se constituem nos trabalhadores e capitalistas duas forças sociais antagônicas, duas classes antagônicas cuja luta está no âmago de toda a dinâmica social destas sociedades. Dinâmica esta, que inclue a possibilidade da própria ruptura de sua lógica como mencionamos antes.

(2) Entretanto, na medida em que a dialética é reflexiva, a luta pela subversão do "sistema" tornou-se fonte de sua renovação (em algumas partes do mundo) e fortalecimento: as conquistas dos trabalhadores revelaram - e aí seguimos o raciocínio de HABERMAS numa interpretação mais livre - que a categoria do trabalho (assalariado) não era suficiente para dar conta da dinâmica - e especialmente das suas contradições - das sociedades capitalistas organizadas durante a fase áurea da presença de um novo "ator" que apenas se consolidava no século XX: o Estado capitalista em geral e o social, em particular, que "intermedia" sistematicamente a relação entre capital e trabalho e, sem romper com os fundamentos da contradição, instala novos mecanismos de distribuição da riqueza social.

Perdendo, então, parcialmente o caráter fundamental (tornando-se um conflito que pode ser transferido entre diferentes agentes e instâncias sociais), mantém seu caráter universal porque os mecanismos de transferência exigem que todos (tanto capital como trabalho - como diz Offe os "proprietários de fatores econômicos") se submetam a esta lógica / dinâmica. Habermas sugere então que a categoria do trabalho não é suficientemente abstrata (aliás, como ele diz, nunca foi o suficiente para compreender o caráter próprio do homem vivendo em sociedade) para compreender a nova situação; é preciso alcançar um patamar mais abstrato com a categoria de interação que engloba além do trabalho, ainda a categoria de comunicação. Nessa formulação a infra-estrutura (forças produtivas) perde seu poder determinante sobre as demais articulações políticas e ideológicas. É o próprio avanço do capitalismo e do Estado social que vai consolidar a institucionalização de duas esferas diferentes naquelas sociedades em torno da produção/administração e da reprodução das condições culturais, sociais e psicológicas que seguem uma outra lógica.

Seguindo Habermas, deve-se supor que haja um antagonismo entre duas formas de interação nas sociedades contemporâneas (em particular, nos países industrializados): uma comunicativa, baseada em atos de fala proferidos com a intenção da mútua compreensão; e uma instrumental-estratégica, baseada numa racionali-

\footnotetext{
${ }^{26}$ São primordialmente direcionados para influenciar o comportamento dos atores, permitir ações "corretas" dentro de contextos institucionais (conforme certas expectativas estruturais) e, neste sentido, representam mais uma transmissão ou troca de informações subordinadas a fins extra-lingüísticos (ordens são um típico exemplo para estes tipos de atos de fala) do que um ato comunicativo de mútua compreensão.
} 
dade orientada por determinados fins. Atos de fala nesta segunda interação entre agentes não tem uma pretensão propriamente dita "comunicativa". ${ }^{26}$

O exercício destas interações foi se estabilizando, no decorrer da consolidação das sociedades modernas, em determinadas esferas da vida social (econômica, política, cultural) onde prevalece (sem ser exclusiva) ou uma lógica comunicativa ou uma lógica instrumental-estratégica. Na medida em que entendemos estas lógicas como excludentes - seguindo Habermas - sua relativa estabilização institucional numa esfera sistêmica e numa esfera do mundo da vida (quadro institucional) das sociedades contemporâneas gera novos antagonismos que não se restringem mais à inserção dos atores em duas classes relacionadas à contradição entre capital e trabalho.

Os sistemas econômico e administrativo dominados pela lógica instrumental (orientada para fins), por um lado, e o quadro institucional onde reina tendencialmente a reprodução social através de processos comunicativos, por outro lado, representam estes diferentes princípios de estruturação social:

(i) numa percepção da sociedade a partir da lógica instrumental (sistêmica), o sistema econômico foi se diferenciando e separando, geneticamente, das demais manifestações e instituições sociais, assumindo após a gradual consolidação do capitalismo a dominação sobre as demais esferas da vida social. Firmou-se na medida em que submeteu à sua lógica não apenas atividades econômicas e administrativas através de princípios hierárquicos e funcionais; mas também através de uma contínua expansão de sua lógica em áreas antes regidas por outros princípios sociais - gerando cada vez novos mercados. E mesmo onde não subverteu estes princípios instituiu mecanismos de troca através de determinados papéis sociais que precisaram estar minimamente ancorados nestas esferas "não" capitalistas.

Assim, o sistema estabelece através de relações de troca mútua os papéis dos trabalhadores (trocando salário por força de trabalho) e dos consumidores (trocando dinheiro por mercadorias). Estabelece, ainda, com isto, uma esfera privada da sociedade, em contraponto a uma esfera pública entre sistemas administrativos que foram se consolidando e estabelecendo suas próprias relações de troca e papéis funcionais (de cliente e contribuinte, neste caso).

Nesta perspectiva sistêmica, o acima mencionado quadro institucional da sociedade reúne as condições de reprodução tanto social como sistêmica e, neste último caso, através da mediação e reprodução dos papéis acima mencionados. Faz parte da lógica instrumental que ela procura ampliar-se para áreas que até então ainda mantiveram outras características (comunicativas). ${ }^{27} \mathrm{O}$ antagonismo estabelece-se na medida em que há uma 'convivência contraditória' entre essas esferas (colonização vs. subversão).

${ }^{27}$ Explicitações mais detalhados vimos elaborando nos últimos anos e podem ser encontradas nos nossos últimos trabalhos, vide, por exemplo, RANDOLPH (1996c). 
(ii) Quando mudamos a perspectiva, o quadro (institucional) apresenta características desapercebidas pelo ponto de vista anterior. $\mathrm{O}$ quadro institucional ou mundo da vida revela seu caráter não-sistêmico exatamente na medida em que os "sujeitos socializados comunicativamente não seriam propriamente dito sujeitos se não houvesse a malha de ordens institucionais e das tradições da sociedade e da cultura. O mundo da vida, então não constitui uma organização à qual os indivíduos pertencem como membros, nem uma associação à qual se integram, nem uma coletividade composta por membros singulares" (HABERMAS, 1990:100). A prática comunicativa cotidiana alimenta-se de um processo conjunto, resultante da reprodução cultural, da integração social e da individuação (formação da personalidade), e esse processo está, por sua vez, enraizado nesta prática.

Neste mundo da vida simbolicamente estruturado os componentes estiveram originalmente entrecruzados e jamais devem ser entendidos como sistemas que formam ambientes uns para os outros. São cultura - encarnada em formas simbólicas -, sociedade - representada por ordens, normas e costumes sociais que orientam as práticas sociais "corretas", aceitas - e as estruturas de personalidade - encarnadas literalmente no substrato dos organismos humanos.

Na prática do cotidiano, "todo o sentido conflui para o mesmo ponto" (HABERMAS, 1990:98); não há distinção ou separação. Não existem três pólos diferentes da vida cotidiana, mas a triplicidade dos três "elementos" já mencionados que se distinguem apenas por diferentes horizontes temporais e espaciais ${ }^{28}$.

Estes elementos cruzam-se entre si através do meio comum que é a linguagem cotidiana. Esta linguagem, multifuncional, levanta barreiras à diferenciação do mundo da vida. É através deste código comum (da linguagem comum) que se mantém em pé uma relação com a totalidade do mundo da vida, apesar das influências segregadoras dos papéis (sistêmicas) acima introduzidas.

A contradição aparece neste novo quadro institucional como incompatibilidade entre produção e reprodução, como falta de sustentabilidade social a médio prazo na medida em que leva ao esgotamento de "recursos sociais" que é incapaz de reproduzir; a crítica weberiana ao capitalismo e ao esvaziamento dos valores culturais e sociais, retomada por Habermas, já apontava nesta direção. A luta é, então, uma luta contra a mercantilização das relações sociais e culturais, da colonização de formas de integração social por relações instrumentais e se manifestou numa

\footnotetext{
${ }^{28}$ Quais sejam: - tradições culturais que se difundem por e sobre fronteiras de coletividades e comunidades de linguagem e sua duração não depende da identidade de sociedades, nem de pessoas; sociedades que envolvem um espaço maior e períodos históricos mais longos do que as pessoas e suas histórias de vida; têm limites menos difusos e mais claramente circunscritos que as tradições; estruturas de personalidade que são, por causa de seu apego aos substratos orgânicos, as mais nitidamente definidas em tempo e espaço; para os indivíduos, a cultura e a sociedade se apresentam, antes de tudo, na figura de um extenso conjunto de gerações.
} 
ampla gama de diferentes formas de protestos, movimentos de contestação e reivindicação, muitas vezes dirigidos contra o Estado.

Neste sentido, ao lado da substituição de lutas por acordos corporativos entre sindicatos de patrões e sindicatos dos trabalhadores - facilitados em períodos de crescimento econômico e pleno emprego - que continuam importantes para a dinâmica sócio-econômica nos países industrializados, este novo quadro institucional do capitalismo organizado tornou impossível atribuir a dinâmica social a uma "luta" entre duas classes tradicionalmente antagônicas. Porque as sociedades apresentam um grau maior de diferenciação, acompanhado por um grau menor de visibilidade (enquanto resultado deliberado das transformações que ocorreram vide novamente Offe). De fato, a partir da década de sessenta, surge uma série de movimentos e mobilizações contestatórios que não têm como foco principal de luta as relações de produção (mesmo quando problematiza exatamente o desenvolvimento das forças produtivas como, por exemplo, o movimento ecológico ${ }^{29}$ ) mas questões relacionadas à articulação entre sistema e mundo da vida, produção e reprodução.

(3) Tanto Castells como nós estamos trabalhando com a hipótese que a recente e cada vez mais acelerada "difusão" de formas "reticulares" de organização econômica, social, política e cultural está gerando uma reformulação fundamental dos antagonismos e contradições que caracterizaram as formações sociais capitalistas até então.

Se partíssemos (histórica e conceitualmente) de um arcabouço habermasiano ${ }^{30}$, a sociedade-rede de Castells caracterizar-se-ia pelo geração de um meta-sistema econômico - o dos fluxos financeiros - que dominará os demais sistemas econômicos e administrativos e levará ao seu mais completo desacoplamento estrutural numa posição de o-posição - com o mundo da vida na medida em que o funcionamento "caótico" deste meta-sistema nem mais pode ser compreendido por aqueles responsáveis pela condução dos sistemas. Esta construção assume uma certa semelhança com os três "andares" braudelianos: o da produção material, o do mercado (sistema) e o das altas finanças onde se encontra o alto comando da economia mundial. Não podemos, aqui, aprofundar este veio (vide o já citado livro de Arrighi sobre o Longo século $X X$ ).

Antes dissemos que a sociedade-rede é paradoxalmente escassa em conexões, ou seja, é altamente seletiva e restrita como "rede" - apenas se constitui de relações ("rede") dentro de uma determinada lógica que é a do capital financeiro; agora podemos dizer que essa sociedade-rede deixa de ser tendencialmente "sociedade" na medida em há um rompimento total entre diferentes esferas que deixam de se

\footnotetext{
${ }^{29}$ Vide nossa pequena reflexão a este respeito em RANDOLPH, BESSA e COSTA (1991).

${ }^{30}$ Que não é adotado por Castells; vide o Prólogo onde indica as referênciais conceituais que orientam sua reflexão;
} 
comunicar (mesmo se fosse de troca de estratégias) e imprimir alguma dinâmica conjunta (mesmo se fosse contraditória).

A comparação com a teoria social crítica conduz a um resultado surprendente em relação à interpretação da sociedade-rede de Castells: observada a partir do ponto de vista do período que lhe deu origem, ela nem parece ser "rede" e muito menos ainda "sociedade". Infelizmente, o primeiro livro do autor não permite reconstruir o processo deste rompimento na medida em que focaliza exclusivamente a lógica instrumental-estratégica da sociedade pré-rede ${ }^{31}$. Acreditamos que esta limitação de análise já está predeterminada pela compreensão que adota em relação às redes:

uma rede é um conjunto de nós interconectados. Um nó é um ponto no qual uma curva apresenta uma interseção com ela mesma (intersects itself). O que um nó é, falando concretamente, depende da espécie da rede concreta da qual estamos falando”.(CASTELLS, 1996:470)

\section{Redes, nós e instrumentos}

É, a nosso ver, esta definição extremanente restrita que leva Castells a uma generalização de uma lógica instrumental e formal como base para todas as conexões possíveis na "sociedade-rede". Talvez motivado pela delimitação da discussão neste primeiro livro, os exemplos que o autor usa para explicitar o significado de nós reforça esta impressão. São nós:

- $\quad$ os mercados das bolsas de valores e seus serviços avançados na rede dos fluxos financeiros globais;

- os conselhos nacionais de ministros e comissários europeus na rede política que governa a União Européia;

- os campos de cocaína, laboratórios clandestinos, pistas secretas de pouso, gangues de rua e instituições de lavagem de dinheiro na rede do tráfico de drogas que penetra em economias, sociedades e Estados no mundo inteiro;

- $\quad$ sistemas de televisão, estúdios de entretenimento, milieus de computação gráfica, novos grupos de trabalho (teams) e unidades móveis que geram, transmitem e recebem sinais na rede global da nova mídia (CASTELLS, 1996:470).

\footnotetext{
${ }^{31}$ É possível que estas questões sejam explicitadas nos volumes consecutivos da "Era da Informação"; 32 "Uma estrutura social baseada em rede é altamente dinâmica, sistema aberto, susceptível de inovar sem ameaça ao seu equilíbrio", (CASTELLS, 1996:470).
} 
Redes são estruturas (abertas, aptas de se expandir, comunicativas, altamente dinâmicas ${ }^{32}$ ) e instrumentos econômicos, sociais e culturais. Cada rede tem topologia, determina distâncias, velocidades (inclusive simultaneidades) e precisa naturalmente de certos suportes materiais, energéticos e informacionais para poder desempenhar suas funções.

A topologia definida por redes determina que a distância (ou intensidade ou freqüência de interação) entre dois pontos (ou posição social) é mais curta (ou mais freqüente ou mais intensa) se os dois pontos fazem parte de uma rede do que se não pertencessem à mesma rede. Por outro lado, dentro de uma rede determinados fluxos não tem distância, ou a mesma distância, entre os nós. Por isto, a distância (física, social, econômica, política, cultural) para um determinado ponto ou posição varia entre zero (para qualquer ponto dentro da mesma rede) e infinito (para qualquer ponto externo à rede). A inclusãolexclusão em redes e a arquitetura de relacionamentos entre redes, realizadas por tecnologias de informação que trabalham na velocidade da luz, configuram processos e funções dominantes em nossas sociedades (CASTELLS, 1996:470).

Uma fonte da reorganização dramática de relacionamentos de poder é também a morfologia de rede:

Interruptores (switches) que conectam redes (por exemplo, fluxos financeiros assumindo o controle de impérios de mídia que influenciam processos políticos) são os instrumentos privilegiados do poder. Por isto, os "switches" [pessoas que operam estas ligações entre redes, observação nossa] são os detentores do poder. Como redes são múltiplas, os códigos interoperacionais $e$ "switches" entre redes representam a fonte fundamental na formação, na condução e desgoverno (misguide) das sociedades. A convergência entre evolução social e tecnologia de informação criou uma nova base material para o desempenho de atividades no seio da estrutura social. Esta base material, erguida em redes, assinala processos sociais dominantes, assim moldando a própria estrutura social

(CASTELLS, 1996:471)

\section{Conclusões: Redes Antagônicas em sociedades complexas}

Além de apresentar um certo viés instrumentalista no seu conceito de rede, parece-nos que a perspectiva de Castells continua tributária a pressupostos estruturais quando diz que a morfologia social vai se impondo à ação social:

\footnotetext{
${ }^{33}$ Novamente cabe destacar que o próprio autor nos adverte que ainda não consegue dar conta da abrangência do tema na medida em que questões tão fundamentais como relações de gênero, construção de identidade, movimento social, a transformação do processo político e a crise do Estado na era da informação só serão tratados nos volumes 2 e 3 de sua obra;
} 
Presença ou ausência na rede e a dinâmica de cada rede vis-à-vis a outras são recursos críticos de dominação e mudança na nossa sociedade: uma sociedade que, por causa disto, podemos chamar corretamente de sociedade-rede, caracterizada pela proeminência da morfologia social sobre a ação social(1996:469). ${ }^{33}$

Para nós, falar de rede significa, além de sua compreensão como uma forma de "integração da diversidade" ${ }^{4}$, a busca de formas de "articulação entre o local e o global, entre o particular e o universal, entre o uno e o diverso, nas interconexões das identidades dos atores com o pluralismo"/(SCHERER-WARREN, 1993:9). Ou seja, articulações que transcendem as formas tradicionais de "sistemas" (e igualmente não-sistemas como o mundo da vida, o cotidiano, as determinações de um quadro institucional de uma sociedade), "estruturas" e mesmo morfologias aparentemente homogêneas (e é esta a impressão que temos do approach de Castells - talvez equivocadamente como os dois volumes da "Era da Informação" poderão mostrar). Em síntese, as redes encontram-se num "ponto de interseção" entre uma heterogeneidade de conteúdos (econômicos, sociais, políticos e culturais) e uma heterogeneidade de formas (locais, regionais, nacionais e mundiais). Uma "sistematização" da concepção das redes poderia usar essas duas dimensões como maneira de identificar suas características (sua "novidade" em relação a abordagens concorrentes), como de fato tentamos no citado trabalho/ (RANDOLPH, 1996b).

O entendimento de uma visão das redes como "unidade do heterogêneo" onde o "heterogêneo" é o antagonismo ou contradição - pode exigir certo esforço e certamente não facilita uma operacionalização o que, num primeiro momento, gera mais complicações do que facilidades para a compreensão dos fenômenos em curso; em termos de eficácia e eficiência de "explicação" não temos, por enquanto, como "competir" com Castells.

Entretanto, na verdade, nossa principal preocupação é menos chegar rapidamente a uma caracterização de uma nova etapa (modo) de desenvolvimento das sociedades capitalistas através do instrumento analítico de "redes", mas procurar compreender o processo de transição e a nova qualidade da "realidade" e das próprias redes (que passa por uma representação "nova" também) que são seu elemento essencial (aí concordamos com Castells). Naturalmente, partimos também da hipótese de que as mudanças que observamos nos nossos próprios trabalhos representam sinais de uma nova "ordem" social (não necessariamente pós-capita-

\footnotetext{
34 Vide RANDOLPH (1996b: 145-163), onde procuramos, tomando como pontos de partida uma breve análise das mais diferentes manifestações de redes e seus relacionamentos com fenômenos supostamente pós-modernos, pós-industriais, pós-socialistas etc., por um lado, e a já citada visão de Ilse Scherer-Warren, por outro, explicitar certas dimensões que poderiam sugerir que a abordagem da rede se cons-titui como um novo paradigma (ou pelo menos ser "veículo" de transição para este novo paradigma);
} 
lista); uma nova etapa do deslocamento dos antagonismos e das contradições (seria aquela da terceira seção deste texto) no próprio seio da sociedade capitalista.

Mas o grande desafio para nós consiste na compreensão do deslocamento (mais ou menos abrupto) de fronteiras entre as diferentes esferas da vida econômica, social, política e cultural das pessoas e instituições que são próprias do período anterior (na verdade, ainda atual) e que darão origem - eis nossa hipótese central a novas formas de totalidades, ou melhor, a uma até então desconhecida forma de articulação entre totalidades e particularidades, onde não fará sentido, por exemplo, distinguir o econômico do social e do político; onde o "verdadeiro econômico" - produtivo - poderá ser o "cultural" - a comunicação - como dizem alguns pós-fordistas ${ }^{35}$, etc.

Por ora não temos elementos suficientes para localizar nosso posicionamento epistemológico-teórico em relação ao da abordagem de Castells ${ }^{36}$; acreditamos que não haja uma oposição, mas apenas dois caminhos diferentes que procuram explicitar e explicar o surgimento de uma nova realidade social-econômica-política-cultural e física com uma idéia-força semelhante: as redes. Onde Castells parte logo para uma hipótese (macro) de uma sociedade-rede em ascensão; e nós ainda estamos nos dedicando a descobrir as características (micro) de certos sinais do "novo" que, de alguma maneira, têm sua origem no "velho" do qual está emergindo (e que não pode também desaparecer totalmente, mesmo quando a transformação se dá mediante rupturas maiores ${ }^{37}$ ). Esperamos conseguir capturar, assim, mesmo aqueles antagonismos e contradições que assumem formas aparentemente cada vez mais sutis e profundas e que, ao nosso ver, são a principal característica desta nova etapa de estruturações diferenciadas do capitalismo na medida em que redefinem exatamente a relação entre o total e parcial, o geral e o particular, o global e o local.

Esta, talvez, seja a principal característica da nossa abordagem em relação a outras que já vêm norteando há um certo tempo (desde o debate sobre uma possível superação da modernidade) estudos sobre o surgimento de uma nova "era". Existem basicamente três ou quatro diferentes posicionamentos que não precisam ser aprofundados no atual texto: são as posições pós-industrial, pós-fordista ou pós-moderna (Vide KUMAR, 1995).

\footnotetext{
${ }^{35}$ Vide, por exemplo, COCCO (1996).

${ }^{36}$ Aguardamos os restantes dois volumes de sua obra.

${ }^{37}$ Sentimo-nos próximos a autores que, como GIDDENS, LASH, BECK, JOAS e THOMPSON, defendem (em relação à passagem para a modernidade) que "não há nem oposição nem evolução retilínea entre tradição e modernidade. Segundo .. \{THOMPSON\}, torna-se possível pensar no processo de auto-formação reflexivo, consciente e aberto que incorpore valores da tradição", Jornal do Brasil, Cad. Idéias, 30/08/97, p. 4 (Myrian Sepúlveda dos Santos).

${ }^{38}$ Parece um termo da moda atualmente e bastante útil; no entanto, seu significado parece bastante dúbio - por isto o colocamos entre aspas.
} 
É, então, nossa hipótese que, no re-arranjo da organização dominante capitalista entre seus principais "protagonistas" 38 (Capital e trabalho, Estado e mercado; Estado e sociedade civil; mercado e formas alternativas de emprego e renda; esfera pública e esfera privada, integração social e integração sistêmica), a ascensão de novas redes é o fator determinante; em outras palavras, os antigos antagonismos e contradições - longe de serem simplesmente extintos - perdem sua eficácia social e política, dando lugar a um padrão mais diferenciado e heterogêneo cujos "protagonistas" são as próprias redes.

É nas formas de antagonismos e contradições que se expressa também a acima referida relação entre o total e o particular. No extremo, um antagonismo pode estar embutido em uma rede só quando ela consegue articular, temporariamente, agentes com interesses divergentes e conflitantes. Vimos anteriormente que nos dois períodos distintos as sociedades capitalistas se "integraram" por contradições uma vez fundamentais e na outra vez gerais (vide a terceira seção deste texto); nossa hipótese do deslocamento das fronteiras nada mais significa que o pressuposto que o segundo padrão de um antagonismo geral está sendo substituído por um outro que ainda não se estabeleceu o suficiente. Imaginamos que seja um padrão mais abstrato que será reflexo e razão, ao mesmo tempo, de um enorme aumento da complexidade das "sociedades". E poderão ser "redes antagônicas" que assumem este papel.

Em outras palavras, do ponto de vista dos parâmetros anteriores de cooperação e conflito, seriam então as próprias redes que "absorvem" dentro de si (ou entre si, uma em relação a outra) certas "parcelas" de antagonismos que vão ser "integradas" temporária e territorialmente em uma "unidade" heterogênea. Consequientemente, antagonismos e contradições perdem sua expressão estrutural e alcançam um novo patamar de complexidade que tanto facilita como dificulta sua condução mais abrangente (tanto pelo conteúdo como pela forma) ${ }^{39}$. Por causa de sua volatilidade circunstancial, estes antagonismos tornam-se fonte de um dinamismo (flexibilidade, rapidez, agilidade, instantaneidade etc.) capaz de alcançar expressões caóticas nunca vistas em formas organizativas tradicionais (velhas redes).

Como já anunciamos antes, os relacionamentos dentro de e entre redes mudam igualmente seu caráter; deixarão de existir, futuramente, redes sociais, econômicas, políticas etc.; redes do "novo tipo" serão ao mesmo tempo econômicas, sociais,

\footnotetext{
${ }^{39}$ Sem poder aprofundar este aspecto aqui, queriamos chamar atenção que esta mutação atingirá os fundamentos do moderno Estado capitalista e sua função mediadora que realçamos em item anterior; e, ao mesmo tempo - naquela "circularidade" característica de construções sociais onde dificilmente se distingue entre causa e efeito - as transformações da "sociedade política" desempanharão um papel central na própria ascensão da sociedade-rede (acelerando-a ou freando-a);

${ }^{40}$ Do mesmo modo imagina-se que a institucionalização da diferenciação entre o "belo", o "justo" e o "verdadeiro" (estética, ética e ciência), obra do esclarecimento e expressão da modernidade tendem a dar lugar a novas formas de "unidades" ou "diversidades".
} 
técnicas, físicas e, antes de mais nada, políticas (isto é, voltadas para resolver seus conflitos internos como fonte de seu dinamismo $)^{40}$.

Procurando explicitar nossa opinião em outras palavras poderiamos tirar a seguinte síntese:

Diante das transformações que procuramos caracterizar acima, não se identifica mais nem uma contradição fundamental (que seja princípio fundante da organização social), nem uma contradição geral (que, apesar de não determinar a organização social e ser mais efeito - de dominação - do que causa, pelo menos atravessa toda a sociedade) nas sociedades onde as redes vão ocupar cada vez mais "espaço". Nos dois períodos anteriormente apontados, este caráter da contradição e sua efetiva expressão na dinâmica social (lutas) assegurava uma "unidade" profundamente dividida das sociedades industriais.

Assim, apesar de todo seu antagonismo, as forças em contradição se encontraram em alguma "síntese" maior que lhes permitiu expressar sua essência: no interior de relações de produção enquanto antagonismo entre duas classes, no primeiro momento; ou numa dinâmica única de produção e reprodução da sociedade baseada na institucionalização de duas lógicas antagônicas, no segundo momento. Cada um dos antagonismos pressupunha algum patamar mais abrangente - uma totalidade que transcendia os antagonismos - onde se digladiaram, senão não haveria de fato uma confrontação ou exercício de contradição.

Essa "totalidade" no pensamento marxiano - às vezes mecanicamente compreendida com "unicidade totalizadora", como disse Ilse Scherer-Warren - tinha sua expressão na base econômica das sociedades capitalistas sobre a qual se erguia uma "edificação" antagônica e contraditória em si (expressão de uma histórica articulação "dialética" 41 entre partes e todo). Com o advento de novas formas organizacionais de regulação daquele antagonismo fundamental, a própria regulação de caráter geral tornou-se fonte "unificadora" das novas lutas entre sistema e mundo da vida.

A passagem para um terceiro momento prenuncia-se por uma reformulação desta fonte unificadora e pela falta, até agora, de alguma alternativa que possa assumir este "papel". Ao contrário, ao que tudo indica, a re-articulação das lógicas comunicativa e instrumental que se encaminha pari passu em direção a um abandono das "fronteiras" que explicitamos anteriormente, apenas multiplica os antagonismos que se tornam mais abstratos e tendencialmente presentes em qualquer

\footnotetext{
${ }^{41}$ Porque a "unidade" está baseada nas contradições entre as "partes" como se verifica facilmente em todas as vertentes do pensamento crítico.

${ }^{42}$ Poderia ser interessante recuperar aqui uma outra noção (ou conceito) que representa uma outra tradição do pensamento sociológico e político que seria a de "comunidade"; pensamos que teremos oportunidade para tocar neste tema na nossa, já anunciada, segunda participação na VI Semana de Planejamento Urbano e Regional;
} 
manifestação social, econômica, cultural, política (redes) - adjetivos que devem progressivamente perder o seu significado tradicional.

Pois, o conjunto das redes não necessariamente constituirá uma totalidade social que assegure sua articulação em um âmbito comum (muitas vezes identificado fisicamente com um determinado território onde convivem as "partes" deste todo) que costumamos chamar de sociedade $e^{42}$. Essa aparente ausência, na nossa visão, de um princípio totalizador (dialético) era, então, a razão para julgarmos necessário problematizar antes de mais nada o relacionamento entre as partes e o todo nestas "novas" sociedades permeadas por redes. Vimos que mesmo Castells não consegue dar uma resposta a estas questões. As características "societais" e "reticulares" de sua sociedade-rede parecem-nos questionáveis.

Portanto, qualquer avanço na descoberta de novas formas de "unidade" ou "totalidade" (em tempos do caos aparente) precisa refletir sobre as condições de sua existência. Sem neste momento aprofundar estas idéias, parece-nos que a obra de Edgar Morin poderá fornecer um norte para esta reflexão na medida em que trabalha com noções como "caos", "complexidade", "abstração", "sistema" etc.; poderá guiarnos ao alcance de uma noção de "totalidade" complexa dentro de uma visão de sistema que transcende a teoria geral dos sistemas. E, assim, indicar caminhos de como lidar com o deslocamento e desaparecimento das fronteiras entre as diferentes esferas da visão habermasiana que resgate este pensamento dentro de um contexto maior - mais "abstrato" - da "complexidade" que será, ela mesma, o "lugar" dos antagonismos e contradições (a dinâmica).

Finalmente, gostaríamos de ousar tecer algumas observações provocatórias a respeito da investigação de Castells e seu conceito de "sociedade-rede" (network society) a partir da nossa compreensão das transformações em curso que acabamos de expor:

À primeira vista e de forma um tanto surpreendente e paradoxal, a análise de Castells parece resultar numa perspectiva mais "conservadora" da nova sociedade do que a nossa hipótese sobre uma nova articulação entre partes e todo. Sua análise focaliza a convergência entre tecnologia e evolução social que, mesmo quando gera mutações fundamentais, a partir da geração de uma nova base material, instala "apenas" uma nova unidade de condução da diversidade do mesmo tipo: uma meta-rede se torna dominante mundialmente e conduz os processos e molda toda a estrutura social.

Mas aqui percebemos apenas a superfície de sua proposta profundamente ambivalente. Pois, dentro da nossa perspectiva de uma "radical"43 redefinição da

\footnotetext{
${ }^{43}$ Não no sentido de uma superação do próprio modo de produção (capitalista), mas de novos modos de regulação que instalam um novo período histórico; lembramos a passagem da formação do industrialismo até o início do século XX para o intervencionismo do Estado que mesmo a "virada neoliberal" não conseguiu reverter totalmente até hoje.
} 
"convivência" sócio-econômico-político-cultural em uma "sociedade" cujos primeiros contornos as redes parecem anunciar, o paradigma de Castells dos fluxos financeiros globais na meta-rede pode ser compreendido de duas maneiras opostas, antagônicas:

Por um lado, a meta-rede financeira pode parecer uma última e derradeira manifestação das redes tradicionais que procuram se impor pela sua lógica unívoca e dominar outras formas de dinâmicas econômicas, sociais, políticas e culturais. Mais um sinal do fim de um ciclo do que marca de um novo tempo seja em forma de uma sociedade-rede ou de outra - opinião que defende também Arrighi, como já mencionamos antes. Mas não deve ser essa a interpretação de Castells que vê na meta-rede dos fluxos financeiros mundiais já a realização da sociedade-rede.

Então, por outro lado, a meta-rede como expressão máxima dos novos tempos provoca uma total des-territorialização e des-historicização, que significa mais do que um simples fim do território e da história na medida em que reverte permanentemente início e fim, próximo e distante, sob uma lógica onde o futuro já estava presente no passado, e o presente nada mais será que o passado tornado promessa do futuro - em síntese, a expressão de uma dinâmica incontrolável cuja própria lógica sem espaço e tempo apenas pode-se cumprir num caos cuja única lógica (enquanto domínio de outras expressões) consiste na sua própria reprodução enquanto caos. Será a instalação da entropia como princípio "social" máximo de uma rede das redes cuja única "finalidade" será a de destruir outras finalidades, isto é, se voltará contra todas as tentativas de reduzir a entropia do "sistema" (através da geração de ordenamentos, articulações e organizações, regulações e instituições etc.). Significará a reversão de todos os processos, o abandono de uma dinâmica com lógica - e portanto de todas as lógicas; sem espaço - portanto em todos os espaços; sem tempo - portanto em todos os tempos; sem protagonista - e portanto de todos os sujeitos. Será a manifestação da antítese de todas as teses, de uma força onipresente e onipotente imprevisível e incontrolável que não está em lugar nenhum e em todos ao mesmo tempo e nunca. Ou seja, ao mesmo tempo "deus" e "diabo" na terra de ninguém e de todos. Simultaneamente o "paraíso" instantâneo e a eterna "perdição".

Ainda seria possível imaginar uma "terceira via", "dialética"? Se a meta-rede for essas expressões todas ao mesmo tempo? Sinal do fim e do começo ao mesmo tempo? Sinal do caos e da universalização? Sinal do instrumento criado pelo homem que escapa de seu controle que, ao se tornar sua maior ameaça, o força para um novo convívio universal entre si, entre grupos, nações, etnias etc? Apocalipse como salvação? Ou salvação no apocalipse?

Enfim, é assim que podemos responder à pergunta levantada no título, que nem era de se responder. Para dizer a verdade, era uma pergunta retórica que se tornou o cerne das nossas preocupações. 
Resumo: O ensaio visa fornecer elementos conceituais da teoria social crítica a fim de permitir: (i) uma leitura crítica da disseminação indiscriminada do termo "rede" e (ii) sua re-apropriação para a caracterização das transformações sociais e territoriais pelas quais passam as sociedades contemporâneas. Interroga, neste sentido, as idéias mais recentemente publicadas por Castells sobre a sociedade em rede, apontando incoerências na abordagem do autor.

Palavras-chave: Redes Sociais, Sociedade em Rede.

\section{NETWORK SOCIETY: PARADISE OR NIGHTMARE?}

Summary: The article aims to supply conceptual elements of the critical social theory in order to allow (i) a critical apreciation of the term "network" indiscriminate dissemination and (ii) its reappropriation to characterize social and territorial transformations that are reshaping contemporary societies. Interrogating, in this sense, the ideas more recently published by Castells related to the network-society, pointing out incoherences in that author's approach.

Keywords: Social Nets, Network Society.

\section{BIBLIOGRAFIA}

ARRIGHI, G (1996): O longo século XX. Dinheiro, poder e as origens de nosso tempo. Rio de Janeiro, São Paulo: Contraponto, Ed. UNESP.

CASTELLS, M (1996): The rise of the network society. Malden, Mass, Oxford. UK: Blackwell Publ., reimpressão 1997 como primeiro volume de sua obra maior sobre a "Era da Informação" (The Information Age. Economy, Society and Culture);

COCCO, G (1996): As dimensões produtivas da comunicação no pós-fordismo. Comunicação \& política, vol. III, $\mathrm{n}^{\circ} 1$, nova série, jan.-abr. pp. 20-33;

DIAS, L. C (1995): Redes: emergências e organização. In: Geografia: conceitos e temas, org. por CASTRO, I. E., GOMES, P.C., CORRÊA, R.L., R.J: Bertrand Brasil, pp. 141-162.

HABERMAS, J (1990): Ações, atos de fala, interações mediadas pela linguagem e mundo da vida. In: idem, Pensamento pós-metafísico. Estudos filosóficos. Rio de Janeiro: Tempo Brasileiro, pp. 65-103.

. Theorie des kommunikativen Handelns, 2. Bde. Frankfurt/M.: Suhrkamp 1981/82 (publicado em espanhol como Teoria de la acción comunicativa (2 vs). Madrid, Taurus, 1989);

HARVEY. D (1989): A condição pos-moderna. São Paulo: Loyola;

KUMAR, K (1995): From post-industrial to post-modern society. New theories of the contemporary world. Oxford, UK, Cambridge, Mass.: Blackwell Publ.

PFEIFFER, W., WEISS, E (1992): Lean Management. Grundlagen der Fuehrung und Organisation industrieller Unternehmen. Berlin: Schmidt. 
RANDOLPH. R (1993a): Rede-ficação (Networking): A geração de redes territoriais como resultado da globalização/fragmentação sócio-econômica. Trabalho apresentado no Seminário Internacional "Território. Globalização e Fragmentação", ANPUR / USP, São Paulo;

(1993b): Novas redes e novas territorialidades. Trabalho apresentado no 3. Simpósio da Geografia Urbana, Rio de Janeiro

(1994): Redes estratégicas e de solidariedade e organização terrirorial: à procura de novas territorialidades. Cadernos IPPUR, ano VIII, $\mathrm{n}^{\circ} 1$, pp. 1727;

(1995): A formação do "Terceiro Setor" no Brasil. Reflexões e indacações empíricas. In: Desenvolvimento social. Desafios e estratégias, org. p. Maria I. D’Ávila Neto, Rio de Janeiro: UNESCO-UFRJ/EICOS pp. 85-106;

(1996): "American way" e redes brasileiras: Novas formas de consumo e sua expressão nas novas redes territoriais.In: Modernidade, exclusão e a espacialidade do futuro, org. por R.L.Farret (Anais do Vi Encontro Nacional da ANPUR 1995) Brasília: ANPUR, pp. 1053-1064;

(1996b): A rede como integração de diversidade - o desafio da análise de múltiplas articulações de processos sociais. In: Anais do VI Colóquio sobre Poder Local, Salvador, Bahia, NPGA/UFBa, pp. 145-163,

(1996c): O planejamento comunicativo é possível? Trabalho apresentado no XIX Encontro Nacional da ANPOCS, outubro 1995, Caxambu, MG (publicado nas séries Estudos e Debates do IPPUR, n. 7);

- (1996d): Telecities. Trabalho apresentado no Seminário "Espaço-Tempo"; Rio de Janeiro: IPPUR/ANPUR;

- (1997a): Comunicação e território: Reorganização do espaço urbano e novas tecnologias de comunicação mediadas por computador (CMC) In: Novos recortes territoriais, novos sujeitos sociais: desafios do planejamento, ANPUR, Anais do VII Encontro Nacional, Recife, MDU/UFPE, vol. 3., pp. 2177-2189;

(1997b): Comunicação, redes e novas espacialidades. Reflexões sobre um programa de pesquisa. Trabalho apresentado no Workshop Internacional "Comunicação, Espaço e Novas Formas de Trabalho", Rio de Janeiro, UFRJ; (1997c): Planejamento local, acordos estratégicos e democracia: o caso do Rio de Janeiro. Trabalho apresentado no XXI Encontro Nacional da ANPOCS, Caxambu;

RANDOLPH, R., BESSA, E., COSTA, A (1991): Meio Ambiente e Análise Territorial: sugestões metodológicas e instrumentais. Rio de Janeiro, Publicações PUR - UFRJ, Série Estudos \& Debates no 47.

RANDOLPH, R, SILVEIRA, C., MENEGAT, E (1993): Solidariedade e Gestão Territorial: Indagações sobre a Atuação das Organizações NãoGovernamentais no Brasil In: Novas e Velhas Legitimidades na 
Reestruturação do Território, org. por Marco Aurélio Figueredo Gomes, ANPUR, Faculdade de Arquitetura, UFBa, p. 77-88.

SANTOS, M (1996): A natureza do espaço. Técnica e tempo. Razão e emoção. São Paulo: HUCITEC.

SCHERER-WARREN, I (1993): Redes de movimentos sociais. São Paulo: Loyola.

SCHERER-WARREN, I (1996): Metodologia de redes no estudo das ações coletivas e movimentos sociais. In: Anais do VI Colôquio sobre Poder Local (1994), NPGA/UFBa, Salvador, pp. 129-142.

SCHERER-WARREN, I (1997): Redes e espaços virtuais. Uma agenda para a pesquisa de ações coletivas na era da informação. Trabalho apresentado no VII Congresso da Sociedade Brasileira de Sociologia, Brasília, UnB;

SYDOW. J (1992): Strategische Netzwerke. Evolution und Organisation. Wiesbaden: Gabler; 